\title{
Constitutive Androstane Receptor Dependent and Independent Modulation of CYP3A2, CYP1A2 by Phenobarbital and Fibrate in Rats' Liver
}

\author{
${ }^{1,2}$ Zein Shaban Ibrahim, ${ }^{3,4}$ Mohamed Mohamed Ahmed, ${ }^{2}$ Mustafa Shukry, \\ ${ }^{2}$ Shawky Mahmoud and ${ }^{5}$ Mayumi Ishizuka \\ ${ }^{1}$ Departments of Physiology, Faculty of Medicine, College of Medicine, Taif University, KSA \\ ${ }^{2}$ Department of Physiology, College of Veterinary Medicine, Kafrelsheikh University, Egypt \\ ${ }^{3}$ Department of Biotechnology, College of Science, Taif University, KSA \\ ${ }^{4}$ Department of Biochemistry, College of Veterinary Medicine, Sadat University, Egypt \\ ${ }^{5}$ Laboratory of Toxicology, Department of Environmental Veterinary Sciences, \\ Graduate School of Veterinary Medicine, Hokkaido University, Sapporo 060-0818, Japan
}

Received 2013-06-08, Revised 2013-07-25; Accepted 2013-08-12

\begin{abstract}
Cytochrome P450 enzymes, CYP3A and CYP1A are major drug metabolizing enzymes in the liver. CYP3A enzymes have a major role in the metabolism of $30-40 \%$ of all used drugs. CYP1A2 is a key enzyme having an important role in the metabolic clearance of $5 \%$ of currently marketed drugs. CYP1A2 participates in the metabolic activation of chemical mutagens in cooked food, therefore its activity is suspected to be one of the possible risk factors determining the carcinogenicity of heterocyclic amines in human beings. In a previous report, we have reported the induction of CYP3A2 and the inhibition of CYP1A2 by Fibrate (CFA) and proved CYP1A2 inhibition to be PPAR $\alpha$-dependent. CYP3A2 and CYP1A2 have been reported to be induced in the liver by Phenobarbital (PB) while Fibrates was reported to induce CYP3A2. However the exact mechanism of the induction of CYP3A2 by CFA and PB and induction of CYP1A2 by PB has not been clarified yet whether it is through Constitutive Androstane Receptor (CAR) or other receptor as PPAR $\alpha$ or Pregnane X Receptor (PXR). We treated Wistar female rats (with normal expression of CAR protein) and Wistar femal Kyoto rats (with low expression of CAR protein) with $\mathrm{PB}$ and Clofibric Acid (CFA). PB caused a high CYP3A2 induction in Wistar female rats and a low induction in (WKY) indicating that PB induced CYP3A2 in a CAR-dependent manner. Interestingly, PB treatment induced CYP1A2 in Wistar female rats and failed to induce it in (WKY) indicating that the induction of CYP1A2 by PB to be CAR-dependent. Moreover CFA induced CYP3A2 protein similarly in both rat strains indicating that CYP3A2 induction by Fibrates is CAR-independent and most probably to be PXR or PPAR $\alpha$-dependent. For the best of our knowledge this is the first report that shows a clear evidence of the CAR-dependent induction of CYP1A2 and CYP3A2 by PB and the CAR-independent induction of CYP3A2 by fibrates.
\end{abstract}

Keywords: CAR, PB, CFA, CYP3A2, CYP1A2

\section{INTRODUCTION}

Cytochrome enzymes are clinically involved in drug-drug interaction. CYP3A constitutes about $20 \%$ of the total CYP protein in the liver (Wojcikowski et al.,
2012). These enzymes play an important role in the catabolism of several endogenous steroids like testosterone, progesterone, cortisol and bile acids (Patki et al., 2003; Bodin et al., 2005). They have also a major role in the metabolism of $30-40 \%$ of all clinically

Corresponding Author: Zein Shaban Ibrahim, Departments of Physiology, Faculty of Medicine, College of Medicine, Taif University, KSA 
used drugs (Evans and Relling, 1999; Zanger et al., 2008). Rat CYP3A2 exhibits a $73 \%$ homology of the amino acid sequence and some substrate preference to human CYP3A4 (Gibson et al., 2002). Rat CYP3A2 and human CYP3A4 are involved in the metabolism of erythromycin, nifedipine, lidocaine, testosterone aflatoxin B1 and benzo (a) pyrene (Gibson et al., 2002; Nedelcheva and Gut, 1994). CYP3A4 is highly expressed in adult liver and small intestine and catalyzes the metabolism of a variety of xenobiotics and endobiotics, including drugs, environmental chemicals, carcinogens and steroid hormones (Lamba et al., 2002). Induction or inhibition of CYP3A4 expression by some drugs is of a major clinical concern for drug-drug interactions in patients receiving multiple CYP3A4metabolizing drugs (Li et al., 2012). Many drugs can up or down-regulate CYP3A4 expression (Luo et al., 2004). Therefore, understanding the mechanisms of CYP3A2 expression in response to clinically used drugs and environmental signals is critically important for drug therapy. Besides being the main CYP in the liver, CYP3A4 is also expressed in the small intestine contributing to first-pass elimination of many drugs (Paine et al., 1996). Luo et al. (2004) reported that in cultured human hepatocytes and in vivo, PXR represents the main signaling pathway for CYP3A4 induction and also stated that at high concentrations, Phenobarbital induced CYP3A4 by direct activation of human PXR. Moreover, Phenobarbital and phenobarbital-like compounds were demonstrated to induce CYP3A4 gene expression through CAR-mediated signaling pathway (Sueyoshi et al., 1999; Xie et al., 2000). CYP1A2 enzyme is constitutively expressed in the liver and catalyzes the metabolism of many drugs, such as theophylline, caffeine, phenacetin and propranolol (Gonzalez, 1992). CYP1A2 is one of the key enzymes having an important role in the metabolic clearance of $5 \%$ of currently marketed drugs (Faber et al., 2005). CYP1A2 participates in the metabolic activation of chemical mutagens in cooked food, such as 2-amino-3methylimidazo[4,5-f]quinoline (IQ), 2-amino-3,8dimethylimidazo[4,5-f]quinoxaline and 2-amino-1methyl-6-phenylimidazo[4,5-b]pyridine (Boobis et al., 1995). The activity of CYP1A2 is suspected to be one of the possible risk factors determining the carcinogenicity of heterocyclic amines in human beings (Zaher et al., 1998). It was demonstrated that CYP1A2 mRNA could be induced by phenobarbital in female C57BL/6Ncrj $(\mathrm{C} 57 \mathrm{BL} / 6)$ mice in in vivo as well as in vitro experiments (Nemoto and Sakurai, 1995). A significant increase of theophylline clearance after chronic Phenobarbital treatment was reported in humans (Saccar et al., 1985). It was reported that phenobarbital treatment of a human hepatocyte culture resulted in a slight increase of the N-3 demethylation of caffeine, which is catalyzed by CYP1A2 in human livers (Ratanasavanh et al., 1990), who suggested the possibility that CYP1A2 is inducible by phenobarbital in humans. Aryl hydrocarbon receptor (AhR) activation regulates the transcription of CYP1A1 and CYP1A2 and several other genes (Nebert et al., 2004). However, CYP1A2 was reported to be induced by Phenobarbital in mice in an AhR-independent manner (Sakuma et al., 1999). CYP1A2 and CYP3A4 constitute the main pool of CYP protein in human liver as CYP1A2 constitute about (1013\%) (Maurel, 1998) and CYP3A constitutes about 20\% of the total CYP protein in the liver (Wojcikowski et al., 2012). CYP1A2 can be induced by cigarette smoking and by a number of polycyclic aromatic hydrocarbons such as TCDD and bnaphthoflavone (Graham and Lake, 2008), while CYP3A4 is strongly inducible by a number of drugs including rifampicin, arbamazepine, barbiturates and corticosteroids. CYP1A2 induction is mainly through activation of the AhR. The mechanism of CYP1A2 induction by Phenobarbital whether it is through CAR or AhR is still unclear. Moreover the induction of CYP3A by Phenobarbital and fibrates whether it is through CAR or PXR or both is still also questionable. In this study we used a fairly good model of two different rat strains that have different CAR expression levels to investigate the mechanism of CYP3A2 induction by Phenobarbital and Clofibric acid and also the induction of CYP1A2 by Phenobarbital. We could strongly prove that CYP3A2 and CYP1A2 induction by $\mathrm{PB}$ is CAR dependent while CYP3A2 induction by CFA is CAR-independent.

\section{MATERIALS AND METHODS}

\subsection{Materials}

Bovine Serum Albumin (BSA), rabbit horseradish peroxidase-labeled anti-goat IgG and Phenobarbital were purchased from Sigma Chemical Co. (St Louis, MO, USA). Diamino-benzidine-tetrahydro-chloride was obtained from Kanto Chemical Co. (Tokyo Japan) and clofibric acid (2-(p-chlorophenoxy)-2- methylpropionic acid) of 97\% purity was from Pfaltz and Bauer, Inc. (NY, USA). Goat anti-rat CYP2B1- Polyclonal antibody, rabbit anti-rat CYP3A2, Goat antirat CYP1A1/1A2 and Goat anti-rat CYP4A1 polyclonal antibodies were from Daiichi Pure Chemical Co., Ltd. (Tokyo, Japan). Rabbit horseradish peroxidase labeled anti-goat $\mathrm{IgG}$ was from Sigma Chemical Co. (St Louis, MO, USA). Goat horseradish peroxidase-labelled anti-rabbit was from Santa Cruz Biotechnology (CA, USA). Goat anti-rat CAR was 
purchased from Santa Cruz Biotechnology (Santa Cruz, CA, USA). Rabbit horseradish peroxidase-labeled anti-goat IgG was from Sigma Chemical Co. (St Louis, MO, USA). Other chemicals and solvents were of analytical grade. ECLPlus chemiluminescence kit was purchased from Amersham Life Science, Cleveland, OH, USA.

\subsection{Animals}

In the first part of the experiment, ten female Wistar and ten female Wistar Kyoto rats aged 7 weeks were obtained from Charlze River, Nakagawa, Yokohama, Japan. 5 rats from each strain were intraperitoneally injected with PB (80 mg kg-1) and rats were sacrificed $24 \mathrm{~h}$ later. In the second part of the experiment, 15 rats from either strain were divided into 3 groups of 5 rats per each group. The first group in each strain was used as a control, the second group was treated with CFA in corn oil and the third group was treated with PB. Rats were housed at $24 \pm 1{ }^{\circ} \mathrm{C}$ with a $12 \mathrm{~h}$ light $/ 12 \mathrm{~h}$ dark cycle and given laboratory food (MR stock, NOSA N Co., Yokohama, Japan) and water ad libitum. All experiments were performed under the supervision and approval of the Institutional Animal Care and Use Committee of Hokkaido University and Taif University. The CFAtreated group was orally administered CFA (300 mg $\left.\mathrm{kg}_{-1}\right)$ at $8 \mathrm{AM}$ for three consecutive days, while all other groups were administered the same volume of corn oil as a vehicle. On the third day at $8 \mathrm{AM}$, the third group received $\mathrm{PB}\left(80 \mathrm{mg} \mathrm{kg}_{-1}\right)$ by intraperitoneal injection, while all other groups were injected with the same volume of saline. Twenty four hours later, rats were sacrificed with carbon dioxide and the livers were removed and perfused with ice-cold buffer I $(50 \mathrm{mM}$ Tris- $\mathrm{HCl}, \mathrm{pH} 7.4 ; 25 \mathrm{mM} \mathrm{KCl} ; 5 \mathrm{mM} \mathrm{MgCl}$; $0.25 \mathrm{mM}$ sucrose; $0.1 \mathrm{mM}$ PMSF). The microsomal fractions from half of the livers were prepared according to the method of Omura and Sato (1964), with slight modifications. Liver samples were minced and homogenized using a Teflon homogenizer in three times their volume of ice-cold $0.1 \mathrm{M}$ Potassium Phosphate Buffer (KPB), pH 7.4. Homogenized samples were centrifuged at $9,000 \mathrm{~g}$ at $4^{\circ} \mathrm{C}$ for $20 \mathrm{~min}$. The supernatant fraction was centrifuged at $105,000 \mathrm{~g}$ at $4^{\circ} \mathrm{C}$ for $70 \mathrm{~min}$ to obtain a mitochondrion-free microsomal pellet. The washed microsomes were then suspended in $0.1 \mathrm{M}$ $\mathrm{KPB}$, pH 7.4, divided into $1.5 \mathrm{ml}$ tubes, snap-frozen in liquid nitrogen then kept at $-80^{\circ} \mathrm{C}$ until use. Microsomal protein concentrations were determined according to the method of Lowry et al. (1951), using BSA as a standard.

\subsection{Nuclear Extraction}

Nuclear protein was isolated from the second half of the liver samples according to the method of Carey et al.
(1987), with slight modifications. Briefly, samples were homogenized in ice-cold buffer I ( $50 \mathrm{mM}$ Tris- $\mathrm{HCl}, \mathrm{pH}$ 7.4; $25 \mathrm{mM} \mathrm{KCl} ; 5 \mathrm{mM} \mathrm{MgCl}$; $0.25 \mathrm{mM}$ sucrose; 0.1 $\mathrm{mM}$ PMSF) using a Teflon homogenizer. The resulting homogenate was centrifuged at $600 \mathrm{~g}$ at $4^{\circ} \mathrm{C}$ for $10 \mathrm{~min}$. Pellets were then homogenized in twice their volume of buffer I. The homogenates were layered onto buffer I containing 2.3 M sucrose (ratio 4:1) and centrifuged at $12,000 \mathrm{~g}$ at $4^{\circ} \mathrm{C} 40 \mathrm{~min}$. The fraction containing thenuclei was washed with buffer I and re-suspended in nuclear lysis buffer (20 mM HEPES, pH 7.8; $1.5 \mathrm{mM}, \mathrm{MgCl}_{2}$; $420 \mathrm{mM} \mathrm{NaCl} ; 0.2 \mathrm{mM}$ EDTA pH $8 ; 1 \mathrm{mM}$ DTT; 0.5 $\mathrm{mM}$ PMSF; 25\% glycerol) and kept on ice for $30 \mathrm{~min}$, then it was centrifuged at $12,000 \mathrm{~g}$ at $4{ }^{\circ} \mathrm{C}$ for $2 \mathrm{~min}$. The resulting supernatant containing the nuclear extract was snap-frozen in liquid nitrogen and kept at- $80^{\circ} \mathrm{C}$ until use. Nuclear protein concentrations were determined according to the method of Lowry et al. (1951), using BSA as a standard.

\subsection{Western Blotting}

Aliquots of liver microsomal protein $(12 \mu \mathrm{g})$ or nuclear protein $(30 \mu \mathrm{g})$ from treated and control rats were applied to $10 \%$ Sodium Dodecyl-Sulfate (SDS) polyacrylamide gels and separated by electrophoresis using a Protean 2 mini 1-D cell (BioRad, Hercules, CA, USA). The proteins were transferred electrophoretically onto nitrocellulose membrane, blocked with 5\% skim milk in Phosphate-Buffered Saline (PBS) containing 1\% Tween 20 for $2 \mathrm{~h}$ at room temperature and probed with the appropriate antibody in PBS containing $1 \%$ Tween 20 on a shaker for $2 \mathrm{~h}$ at room temperature. Horseradish peroxidase-labeled anti-goat IgG or anti-rabbit IgG were used as secondary antibodies. Immunoreactive protein bands were revealed either by oxidation of $0.025 \% 3,3-$ diaminobenzidine tetrahydrochloride with $0.0075 \%$ hydrogen peroxide catalyzed by peroxidase in 50 mMTris- $\mathrm{HCl}$ ( $\mathrm{pH} 7.6)$, or by detection with the ECLPlus kit using Polaroid Camera. Intensities of the immunoreactive bands were analyzed densitometrically using the public domain NIH Image program www.rbs.info.nih.gov/nih-image.

\subsection{RNA Extraction}

Total RNA was isolated from $50 \mathrm{mg}$ liver tissues using Tri Reagent (Sigma Chemical Co.; St. Louis, MO, USA). Briefly, liver tissue samples were homogenized in $1 \mathrm{ml}$ Tri Reagent, then $0.3 \mathrm{~mL}$ chloroform was added to the sample. The mixture was then shaken for $30 \mathrm{~s}$ and centrifuged at $4^{\circ} \mathrm{C}$ and $12,000 \mathrm{~g}$ for $20 \mathrm{~min}$. The supernatant layers were transferred to a new set of tubes 
and equal volumes of isopropanol were added to the samples, vortexed for $15 \mathrm{~s}$ and centrifuged at $4^{\circ} \mathrm{C}$ and $12,000 \mathrm{~g}$ for $15 \mathrm{~min}$. The RNA pellets were washed with $70 \%$ ethanol. RNA was Dissolved in Deionized, Diethylpyrocarbonate (DEPC) water. Concentration of prepared RNA samples were checked by measuring optical density at $260 \mathrm{~nm}$. The integrity and quality of the prepared RNA samples were checked by agarose gel electrophoresis and by determining OD260/OD280 ratio which was 1.7-1.9 for all samples.

\subsection{RT-PCR}

cDNA was synthesized as follows: A mixture of 5 $\mu \mathrm{g}$ total RNA and $0.5 \mathrm{ng}$ oligo dT primer, in a total volume of $24 \mu \mathrm{L}$ sterilized ultra-pure water, was incubated at $70^{\circ} \mathrm{C}$ for $10 \mathrm{~min}$ and then removed from the thermal cycler. The mixture was made up to $40 \mu \mathrm{L}$ using $8 \mu \mathrm{L}$ RT-buffer (5X), $2 \mu \mathrm{L} 10 \mathrm{mM}$ dNTP, $4 \mu \mathrm{L}$ DEPC water and $2 \mu \mathrm{L}$ reverse transcriptase (Toyobo Co., Ltd, Osaka, Japan). The mixture was then re-incubated in the thermal cycler at $30^{\circ} \mathrm{C}$ for $10 \mathrm{~min}$, at $42^{\circ} \mathrm{C}$ for $1 \mathrm{~h}$ and at $90^{\circ} \mathrm{C}$ for $10 \mathrm{~min}$ to prepare the cDNA. Semi-quantitative PCR for $\beta$-actin and PXR mRNA was performed as follows: $1 \mu \mathrm{L}$ aliquots of the synthesized cDNA was added to $19 \mu \mathrm{L}$ of a mixture containing sterilized ultrapure water, $2 \mu \mathrm{L}$ PCR buffer (10X), $2 \mu \mathrm{L}$ dNTP $(2.5$ $\mathrm{mM}), 0.3 \mu \mathrm{l}$ sense and $0.3 \mu \mathrm{L}$ anti-sense specific primers $(100 \mathrm{pM})$ and $0.1 \mu \mathrm{L}$ EX-Taq polymerase (Takara, Kyoto, Japan). Amplification was initiated by denaturation with one cycle at $94^{\circ} \mathrm{C}$ for 4 min followed, in each cycle, by denaturation at $94^{\circ} \mathrm{C}$ for $1 \mathrm{~min}$ and annealing at $\left(56^{\circ} \mathrm{C}\right.$ for $\beta$-actin and $58^{\circ} \mathrm{C}$ for PXR) for 1 min, extension at $72^{\circ} \mathrm{C}$ for $1 \mathrm{~min}$ and a final incubation for $7 \mathrm{~min}$ at $72^{\circ} \mathrm{C}$ after the last cycle of amplification using a DNA thermal cycler (BioRad). The primer used for $\beta$-actin was forward 5'ATGTACGTAGCCATCCAGGC-3' and reverse 5'TCCACACAGAGTACTTGCGC-3', accession number Accession V01217. The primer for PXR mRNA amplification was PXR forward, 5'AAGACGGCAGCATCTGGAACT-3' and the reverse was 5'-CGCCCTTGAACATGTAGGTTG-3'. (Accession number AF 151377). Amplified PCR products were subjected to electrophoresis using 1.0$1.5 \%$ agarose gels. Bands were stained with ethidium bromide and visualized by ultraviolet illumination and photographed. Intensities of the bands were densitometrically analyzed on a Macintosh computer using the public domain NIH image program.

\subsection{Statistical Analysis}

All data are expressed as means \pm SDs. Statistical significance was evaluated using the Tukey-Kramer
HSD difference (JMP; SAS Institute, Cary, NC, USA) test. Results were considered to be statistically significant at the $\mathrm{p}<0.05$ level.

\section{RESULTS}

\subsection{Effect of PB Treatment on CYP2B Protein expression and CAR Protein Nuclear Translocation in Wistar Female Rats and Wistar Kyoto Female Rats}

Treatment of both rat strains with $\mathrm{PB}$ showed that CYP2B1/2 protein were highly induced in female Wistar rats while their levels were very low in Wistar Kyoto female rats (Fig. 1A), Investigation of the nuclear translocation of CAR protein showed low levels of CAR protein in the nuclear extract of female Wistar Kyoto female rats compared to those of female Wistar rats (Fig. 1B). The low levels of CYP2B $1 / 2$ induction in female Wistar Kyoto female rats compared to those of female Wistar rats and the low level of nuclear CAR protein in female Wistar Kyoto rats confirm their validity for use in this study.

\subsection{Effect of $P B$ and CFA Treatment on CYP3A2 Protein Expression and CAR Protein Nuclear Translocation}

CYP3A2 protein was induced by PB than control in both rat strains, However its induction by $\mathrm{PB}$ was much higher Wistar female rats than Wistar Koyoto female rats. Interestingly, CYP3A2 protein was induced by CFA in a similar level in both rat strains (Fig. 2A). To track the mechanism behind this we measured the nuclear translocation of CAR protein. CFA treatment induced nuclear translocation of CAR to a greater extent than in the control in both strain. PB treatment showed low level of CAR nuclear translocation compared to CA treatment groups in both rat strains (Fig. 2B).

\subsection{Effect of PB and CFA Treatment on PXR mRNA Expression}

Measurement of PXR mRNA expression by RTPCR showed that PB treatment did not affect PXR. CFA treatment induced PXR mRNA expression in both rat strain (Fig. 3), this raise the possibility of PXR activation by CFA and indicates that CFA may act in upstream of the PXR transcription pathway, a mechanism through which CFA induces CYP3A2. 


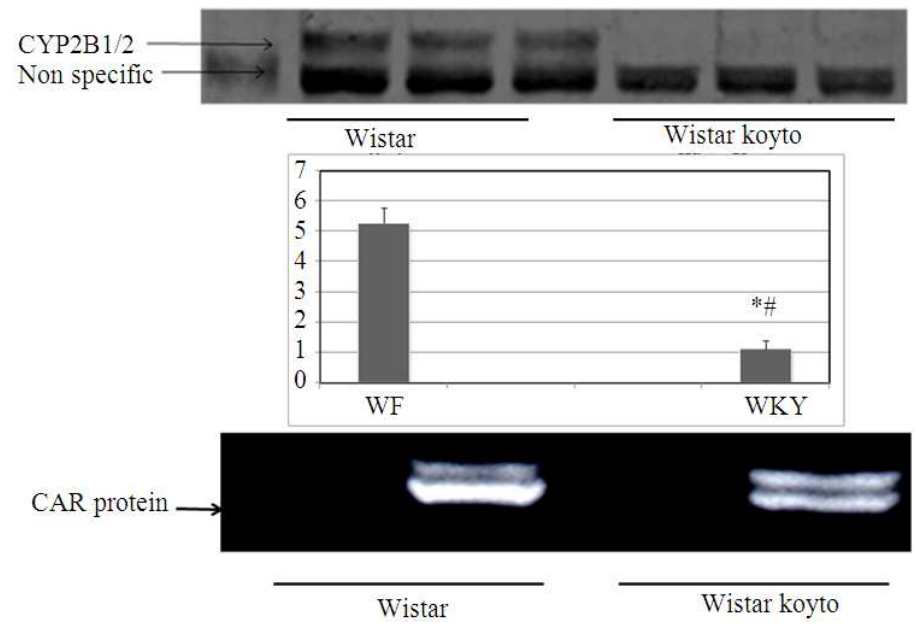

Fig. 1. Effect of Phenobarbital treatment on CYP2B1/2 protein and CAR protein nuclear translocation in Wistar female rats and

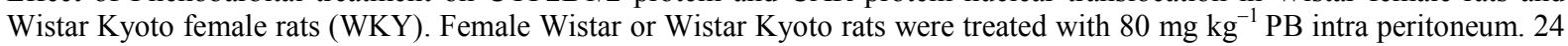
$\mathrm{h}$ later, rats were sacrificed with $\mathrm{CO}_{2}$. Microsomal protein $(12 \mu \mathrm{g} / \mathrm{lane})$ samples were applied to $10 \%$ SDS-PAGE, transblotted onto nitrocellulose membranes and reacted with CYP2B antibodies, as described in the Materials and Methods. (A) CYP2B protein expression due to PB treatment. (WF) Wistar rats while (WKY) Wistar Kyoto rats, Representative blots and results of densitometric analyses of 5 rats from each strain are shown. Values are means \pm SD. *\# lower than Wistar female rats $\mathrm{p}<0.05$. (B) Nuclear protein extracts were prepared from liver samples. Cytosol or nuclear protein samples (30 $\mu \mathrm{g} / \mathrm{lane}$ ) were applied to $10 \%$ SDS-PAGE, transblotted onto nitrocellulose membranes and reacted with CAR antibodies, as described in the Materials and Methods. [WF] denotes Wistar female rats [WKY] denotes Wistar Kyoto female rats, [C] denotes cytosolic protein and $[\mathrm{N}]$ denotes nuclear protein

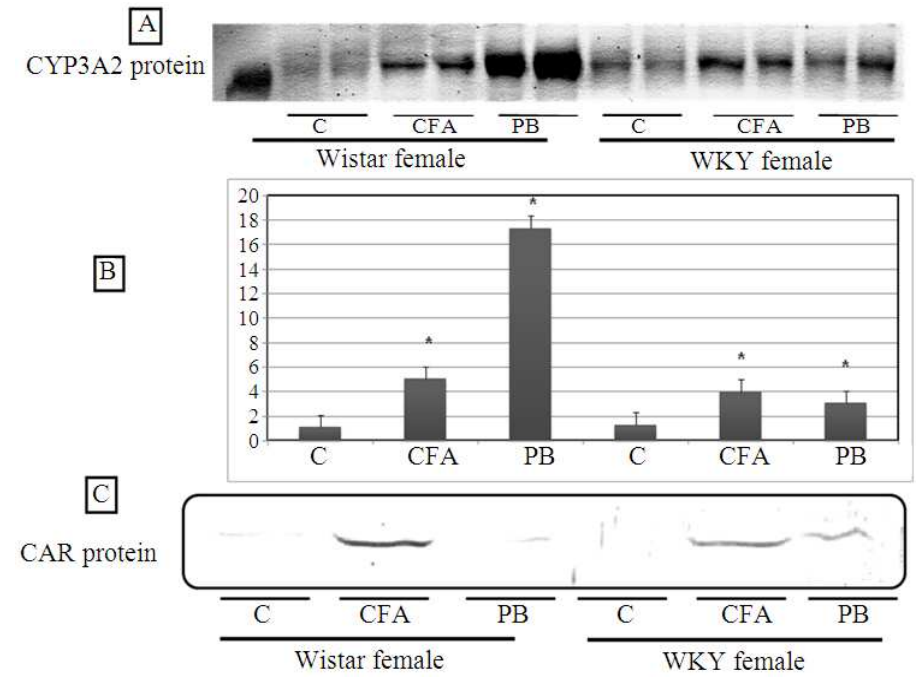

Fig. 2. Effect of $\mathrm{PB}$ and CFA treatment on CYP3A2 protein expression and CAR protein nuclear translocation. Female Wistar or Wistar Kyoto rats were treated with $300 \mathrm{mg} \mathrm{kg}^{-1} \mathrm{CFA}$ for 3 days or $80 \mathrm{mg} \mathrm{kg}^{-1} \mathrm{~PB}$ intra peritoneum $24 \mathrm{~h}$ prior to sacrifice with $\mathrm{CO}_{2}$. (A) CYP3A2 protein expression. Microsomal protein $(12 \mu \mathrm{g} / \mathrm{lane})$ was applied to $10 \%$ SDS-PAGE, transblotted onto nitrocellulose membranes and reacted with CYP3A2 antibodies as described in the Materials and Methods. (B) Results of densitometric analyses of 5 rats from each group are shown. Data are presented in columns representing Mean + SD. * Significantly higher than control in Wistar rats $p<0.05$. (C) Nuclear CAR protein expression. Nuclear protein extracts were prepared from liver samples. Nuclear protein samples $(30 \mu \mathrm{g} / \mathrm{lane})$ were applied to $10 \% \mathrm{SDS}$-PAGE, transblotted onto nitrocellulose membranes and reacted with CAR antibodies, as described in the Materials and Methods. (C) denotes control, (CFA) clofibric acid, (PB) phenobarbital. Representative blots of 5 rats in each treated groups are presented 


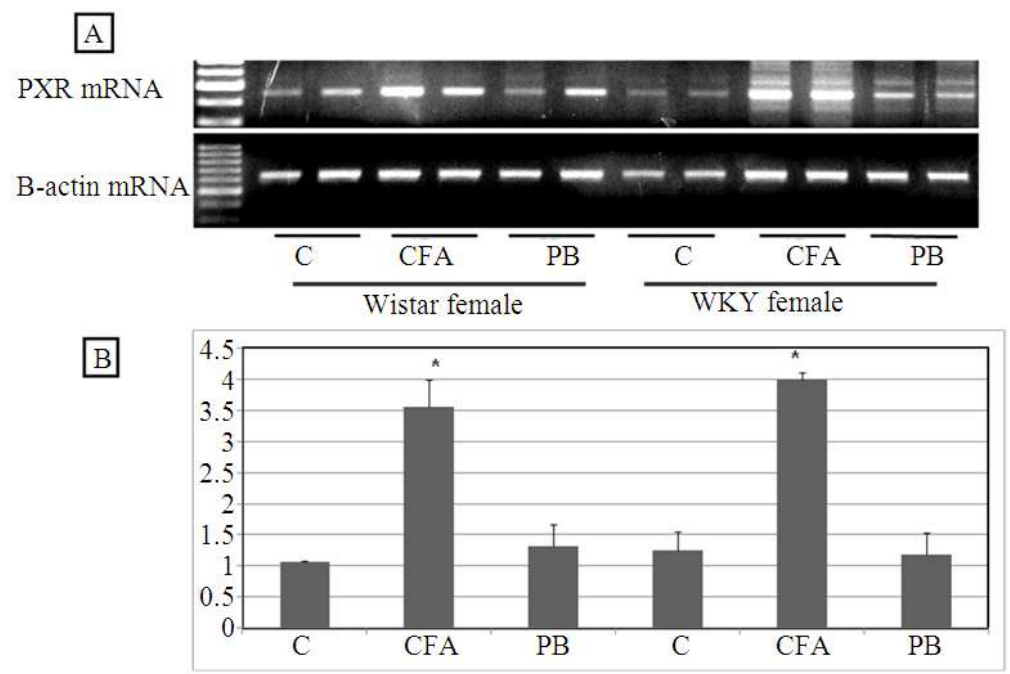

Fig. 3. Effect of PB and CFA treatment on PXR mRNA expression (A) PXR mRNA expression Semi-quantitative PCR was performed to estimate the expression level of PXR mRNA in each treated group of both rat strains. Total RNA was isolated and RT-PCR was performed as described in the Materials and Methods. cDNA samples were amplified in PCR tubes using 25 cycles for $\beta$-actin mRNA (lower panel) and 30 cycles for PXR mRNA amplification (upper panel). PXR mRNA upper panel were normalized to its corresponding B-actin mRNA bands and then calculated relative to the mean values in Wistar rats control group. (B) Results of densitometric analyses of 5 rats from each group are shown. Data are presented in columns representing Mean + SD. *Significantly higher than Wistar rats control group $\mathrm{p}<0.05$. (C) denote control, (CFA) denote clofibric acid treated, (PB) denote Phenobarbital treated

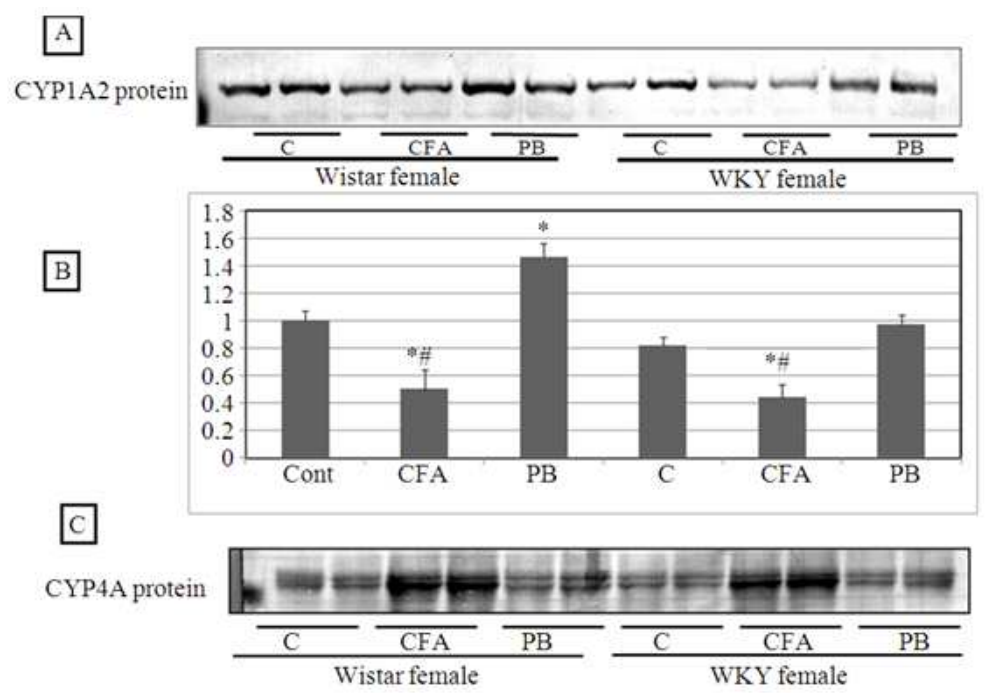

Fig. 4. Effect of CAR protein level on CYP1A2 induction by PB and inhibition by CFAFemale Wistar or Wistar Kyoto rats were treated with $300 \mathrm{mg} \mathrm{kg}^{-1} \mathrm{CFA}$ for 3 days or $80 \mathrm{mg} \mathrm{kg}^{-1} \mathrm{~PB}$ i.p., for $24 \mathrm{~h}$ prior to sacrifice with $\mathrm{CO}_{2}$. (A) Effects of CFA or PB treatment on CYP1A2 in Wistar female and Wistar Kyoto female rats. Microsomal protein $(12 \mu \mathrm{g} / \mathrm{lane})$ was applied to $10 \%$ SDS-PAGE, transblotted onto nitrocellulose membranes and reacted with CYP1A1/1A2 antibodies as described in the Materials and Methods. (B) Results of densitometric analyses of 5 rats from each group are shown. Data are presented in columns representing Mean + SD. * Significantly higher than control in Wistar rats $\mathrm{p}<0.05$. (C) Effects of CFA or PB treatment on CYP4A1. Microsomal protein $(12 \mu \mathrm{g} / \mathrm{lane})$ was applied to $10 \%$ SDS-PAGE, transblotted onto nitrocellulose membranes and reacted with CYP4A1 antibodies as described in the Materials and Methods. (C) denotes control, (CFA) clofibric acid, (PB) phenobarbital. Representative blots of 5 rats in each treated groups are presented 


\subsection{Effect of CAR Protein Level on CYP1A2 Induction by $P B$ and Inhibition by CFA}

PB treatment induced CYP1A2 protein in Wistar rats having normal level of CAR protein but not in Wistar female Kyoto rats have low level of CAR protein (Fig. 4A) indicating the PB-induction of CYP1A2 is CAR dependent. Treatment of rats with CFA inhibited CYP1A2 protein expression than control to the same level in rat both strains indicating the inhibition of CYP1A2 by CFA is CAR-independent. To confirm the effect of CFA we measured CYP4A protein, the main target for PPAR $\alpha$. CYP4A protein was induced by CFA to the same extent in both rat strains only in the CFA acid treated groups (Fig. 4B) As CYP4A is the target of PPAR $\alpha$, its induction indicate the activation of PPAR $\alpha$. This result combined with the result showing CYP3A2 induction with CFA treatment raise the possibility that CYP3A2 induction by CFA to be through PPAR $\alpha$.

\section{DISCUSSION}

CYP3A is the most abundant isoform of CYP metabolizing enzyme in human liver as it metabolizes more than $50 \%$ of current clinical drugs (Wacher et al., 1995). Induction or inhibition of CYP3A4 expression by some drugs is a major clinical concern for drug-drug interactions in patients receiving multiple CYP3A4metabolizing drugs (Li et al., 2012). In a previous study, we have reported that PPAR $\alpha$ ligand (CFA) induced CYP3A2 in rat liver (Shaban et al., 2005) however the mechanism of that induction was not clear. In this study PB highly induced CYP3A2 (16 folds) in Wistar rats having normal CAR expression but, slightly induced CYP3A2 (three folds) in WKY rats having low level of CAR expression which indicates that $\mathrm{PB}$ induces CYP3A2 mainly in a CAR- dependent manner (Fig. 2). The CAR-dependent induction of CYP3A2 with PB treatment is in line with the data reported in a previous study (Ueda et al., 2002). This also is in accordance with a previous in vitro study showed that CAR-RXR heterodimer can bind to the ER6 responsive element of the human CYP3A4 gene and mediated PB-dependent expression in a stable HepG2 cell line (Czekaj, 2000). Notably, PB did not show a high nuclear translocation of CAR protein compared to control. Indeed, PB was reported to induce CAR activation without binding to the receptor through unknown mechanism (Moore et al., 2000). Recently, it was demonstrated that the Phenobarbital induced mechanism of CAR dephosphorylation and activation is mediated through its direct interaction with and inhibition of EGFR
(Mutoh et al., 2013). CFA induced CAR nuclear translocation in both strains than control and $\mathrm{PB}$ treated groups. This may indicate the ability of CFA to bind to and activate CAR. In the current study the up-regulation of nuclear CAR protein in the CFA-treated groups indicates the high possibility of CFA to be a direct ligand and activator of CAR. However, this still needs more elucidation. In spite of the different level of nuclear CAR protein induction in Wistar female rats and Wistar Kyoto female rats due to CFA treatment, it induced CYP3A by similar levels in both rat strains which indicates that its way for CYP3A induction is CAR-independent. In parallel with CYP3A induction with CFA treatment, PXR mRNA was up-regulated with CFA treatment in both rat strains. This in addition to PPAR $\alpha$ activation manifested by CYP4A induction with CFA imply that CFA induces CYP3A in a PXR-dependent or in a PPAR $\alpha$-dependent manner or through activation of both receptors however it still needs further elucidations. CYP1A2 mRNA was demonstrated to be induced by phenobarbital in female C57BL/6Ncrj (C57BL/6) mice in vivo as well as in vitro experiments (Nemoto and Sakurai, 1995). CYP1A2 is one of the key enzymes in the metabolic clearance of $5 \%$ of currently marketed drugs (Faber et al., 2005). It participates in the metabolic activation of chemical mutagens in cooked food, (Boobis et al., 1995). In our study we used two different rat strains containing different levels of CAR protein expression and demonstrated that $\mathrm{PB}$ was able to induce CYP1A2 protein only in the rat strain having normal CAR protein expression while it fails to induce CYP1A2 in the Wistar female Kyoto rats having a low CAR protein expression which gives a clear proof that the PBinduction of CYP1A2 is a CAR-dependent. The induction of CYP1A2 by PB is in accordance with the data demonstrated a significant increase of theophylline clearance after chronic Phenobarbital treatment in humans (Saccar et al., 1985). The activity of CYP1A2 is suspected to be one of the possible risk factors determining the carcinogenicity of heterocyclic amines in human beings (Zaher et al., 1998). The substrates for P450s enzymes are highly lipophilic. In the process of metabolizing some compounds, the P450 system can catalyze the formation of reactive metabolites that can lead to toxicity and/or carcinogenesis (Guengerich et al., 2003). It is known that the cytochrome P450 family generates ROS as byproducts of microsomal oxidation. It was stated that the production of ROS due to increased CYP1A expression is induced not only by classical AhR ligand but also the atypical non-AhR ligand (Dewa et al., 2009). Then it was recently speculated by Hayashi et al. (2012) that most CYP1A inducers have ROS-mediated 
liver tumor promoting activities in rats. Moreover, PB was suggested to synergize with orphenadrine in livertumor promoting activity resulting from oxidative stress due to enhanced ROS production (Morita et al., 2013). The CAR-dependent induction of CYP1A2 by PB that we demonstrated in this study may explain the tumorpromoting effect of $\mathrm{PB}$.

\section{CONCLUSION}

We here present a clear proof of the CAR-dependent induction of CYP3A2 by $\mathrm{PB}$ and CAR-independent induction of CYP3A2 by CFA. Moreover, we present a clear evidence of CAR-dependent induction of CYP1A2 by $\mathrm{PB}$. For the best of our knowledge this is the first report shows a clear evidence of the CAR-dependent induction of CYP1A2 and CYP3A by PB.

\section{ACKNOWLEDGMENT}

This study was supported in part the Grants-in-Aid for Scientific Research from Japan Society for the Promotion of Science (JSPS) awarded to Shaban et al. (2004) (No. P05214) and by the Grant-in-Aid of the Dean of Scientific Research (No.1833-433-1), Faculty of Medicine, Taif University, Saudi Arabia. The authors would like to thank Prof. Shoichi Fujita Laboratory of Toxicology, Dept of Environmental Science, Graduate School of Veterinary Medicine, Hokkaido University (N18, W9, Kita-ku, 060-0818 apporo, Japan) for his generous and continuous support.

\section{REFERENCES}

Bodin, L., C. Verstuyft, D.A. Tregouet, A. Robert and L. Dubert, 2005. Cytochrome P450 2C9 (CYP2C9) and vitamin $\mathrm{K}$ epoxide reductase (VKORC1) genotypes as determinants of acenocoumarol sensitivity. Blood, 106: 135-140. DOI: 10.1182/blood-2005-010341 .

Boobis, A.R., N.J. Gooderham, K.J. Rich, K. Zhao and R.J. Edwards et al., 1995. Enzymatic studies of the activation of heterocyclic food mutagens in man. Princess Takamatsu Symp., 23: 134-144. PMID: 8844804.

Carey, D.J., C.M. Rafferty and M.M. Schramm, 1987. Association of heparan sulfate proteoglycan and laminin with the cytoskeleton in rat liver. J. Biol. Chem., 262: 3376-3381. PMID: 3818646

Czekaj, P., 2000. Phenobarbital-induced expression of cytochrome P450 genes. Acta Biochim. Pol., 47: 1093-1095. PMID: 11996099
Dewa, Y., J. Nishimura, M. Jin, M. Kawai and Y. Saegusa et al., 2009. Molecular expression analysis of beta-naphthoflavone-induced hepatocellular tumors in rats. Toxicol. Pathol., 37: 446-455. DOI: 10.1177/0192623309335062

Evans, W.E. and M.V. Relling, 1999. Pharmacogenomics: Translating functional genomics into rational therapeutics. Science, 286: 487-491. DOI: 10.1126/science.286.5439.487

Faber, M.S., A. Jetter and U. Fuhr, 2005. Assessment of CYP1A2 activity in clinical practice: Why, how and when? Basic Clin. Pharmacol. Toxicol., 97: 125134. DOI: $10.1111 / \mathrm{j} .1742-7843.2005$.pto_973160.x

Gibson, G.G., N.J. Plant, K.E. Swales, A. Ayrton and W. El-Sankary, 2002. Receptor-dependent transcriptional activation of cytochrome P4503A genes: Induction mechanisms, species differences and interindividual variation in man. Xenobiotica, 32: 165-206. DOI: 10.1080/00498250110102674

Gonzalez, F.J., 1992. Human cytochrome P450: Problems and prospects. Trends Pharmacol. Sci., 13: 346-352. DOI: 10.1016/0165-6147(92)90107-

Graham, H.M.J. and B.G. Lake, 2008. Induction of drug metabolism: Species differences and toxicological relevance. Toxicology, 254: 184-191. DOI: 10.1016/j.tox.2008.09.002

Guengerich, F.P., I.H. Hanna, M.V. Martin and E.M.J. Gillam, 2003. Role of glutamic acid 216 in cytochrome P450 2D6 substrate binding and catalysis. Biochemistry, 42: 1245-1253. DOI: 10.1021/bi027085w

Hayashi, H., K. Shimamoto, E. Taniai, Y. Ishii and R. Morita et al., 2012. Liver tumor promoting effect of omeprazole in rats and its possible mechanism of action. J. Toxicol. Sci., 37: 491-501. PMID: 22687989.

Lamba, J.K., Y.S. Lin, E.G. Schuetz and K.E. Thummel, 2002. Genetic contribution to variable human CYP3A-mediated metabolism. Adv. Drug. Deliv. Rev., 54: 1271-1294. DOI: 10.1016/S0169409X(02)00066-2

Li, D., R. Gaedigk, S.N. Hart, J.S. Leeder and X.B. Zhong, 2012. The role of CYP3A4 mRNA transcript with shortened 3'-untranslated region in hepatocyte differentiation, liver development and response to drug induction. Mol. Pharmacol., 81: 86-96. DOI: 10.1124/mol.111.074393

Lowry, O.H., N.J. Rosebrough, A.L. Farr and R.J. Randall, 1951. Protein measurement with the Folin phenol reagent. J. Biol. Chem., 193: 265-275. PMID: 14907713 
Luo, G., T. Guenthner, L.S. Gan and W.G. Humphreys, 2004. CYP3A4 induction by xenobiotics: Biochemistry, experimental methods and impact on drug discovery and development. Curr. Drug. Metab., 5: 483-505. DOI: 10.2174/1389200043335397

Maurel, P., 1998. Drug metabolizing enzymes. Curr. Opin. Crit. Care, 4: 213-218. DOI: 10.1097/00075198-199808000-00001

Moore, L.B., D.J. Parks, S.A. Jones, R.K. Bledsoe and T.G. Consler et al., 2000. Orphan nuclear receptors constitutive androstane receptor and pregnane $\mathrm{X}$ receptor share xenobiotic and steroid ligands. J. Biol. Chem., 275: 15122-15127. DOI: 10.1074/jbc.M001215200

Morita, R., A. Yafune, A. Shiraki, M. Itahashi and H. Akane et al., 2013. Enhanced liver tumor promotion activity in rats subjected to combined administration of phenobarbital and orphenadrine. J. Toxicol. Sci., 38: 415-424. DOI: 10.2131/jts.38.415

Mutoh, S., M. Sobhany, R. Moore, L. Perera and L. Pedersen et al., 2013. Phenobarbital indirectly activates the constitutive active androstane receptor (Car) by inhibition of epidermal growth factor receptor signaling. Sci. Signal, 7: 31-31. DOI: 10.1126/scisignal.2003705

Nebert, D.W., T.P. Dalton, A.B. Okey and F.J. Gonzalez, 2004. Role of arylhydrocarbon receptor-mediated induction of the CYP1 enzymes in environmental toxicity and cancer. J. Biol. Chem., 279: 23847 23850. DOI: $10.1074 /$ jbc.R400004200

Nedelcheva, V. and I. Gut, 1994. P450 in the rat and man: Methods of investigation, substrate specificities and relevance to cancer. Xenobiotica, 24: 1151-1175. DOI: 10.3109 /00498259409038673

Nemoto, N. and J. Sakurai, 1995. Glucocorticoid and sex hormones as activating or modulating factors for expression of Cyp2b-9 and Cyp2b-10 in the mouse liver and hepatocytes. Arch. Biochem. Biophys., 319: 286-292. DOI: 10.1006/abbi.1995.1294

Omura, T. and R. Sato, 1964. The carbon monoxidebinding pigment of liver microsomes. II. Solubilization, purification and properties. J. Biol. Chem., 239: 2379-2385. PMID: 14209972

Paine, M.F., D.D. Shen, K.L. Kunze, J.D. Perkins and C.L. Marsh et al., 1996. First-pass metabolism of midazolam by the human intestine. Clin. Pharmacol. Ther., 60: 14-24. DOI: 10.1016/S00099236(96)90162-9
Patki, K.C., L.L.V. Moltke and D.J. Greenblatt, 2003. In vitro metabolism of midazolam, triazolam, nifedipine and testosterone by human liver microsomes and recombinant cytochromes p450: Role of Cyp3a4 and Cyp3a5. DMD, 31: 938-944. DOI: $10.1124 / \mathrm{dmd} .31 .7 .938$

Ratanasavanh, D., F. Berthou, Y. Dreano, P. Mondlne and A. Guillouzo et al., 1990. Methylcholanthrene but not phenobarbital enhances caffeine and theophylline metabolism in cultured adult human hepatocytes. Biochem. Pharmacol., 39: 85-94. DOI: 10.1016/0006-2952(90)90651-Z

Saccar, C.L., M. Danish, M.C. Ragni, M.L. Rocci and J. Greene et al., 1985. The effect of phenobarbital on theophylline disposition in children with asthma. J. Allergy Clin. Immunol., 75: 716-719. DOI: 10.1016/0091-6749(85)90099-5

Sakuma, T., M. Ohtake, Y. Katsurayama, K. Jarukamjorn and N. Nemoto, 1999. Induction of CYP1A2 by phenobarbital in the livers of aryl hydrocarbonresponsive and-nonresponsive mice. Drug Metab. Dispos., 27: 379-384. PMID: 10064569

Shaban, Z., M. Soliman, S. El-Shazly, K. El-Bohi, A. Abdelazeez and K. Kehelo et al., 2005. AhR and PPARalpha: Antagonistic effects on CYP2B and CYP3A and additive inhibitory effects on CYP2C11. Xenobiotica, 35: 51-68. DOI: 10.1080/00498250400021804

Shaban, Z., S. El-Shazly, M. Ishizuka, K. Kimura and A. Kazusaka et al., 2004. PPARalpha-dependent modulation of hepatic CYP1A by clofibric acid in rats. Arch. Toxicol., 78: 496-507. DOI: 10.1007/s00204-004-0569-9

Sueyoshi, T., T. Kawamoto, I. Zelko, P. Honkakoski and M. Negishi, 1999. The repressed nuclear receptor CAR responds to phenobarbital in activating the human CYP2B6 gene. J. Biol. Chem., 274: 60436046. DOI: $10.1074 / \mathrm{jbc} .274 .10 .6043$

Ueda, A., H.K. Hamadeh, H.K. Webb, Y. Yamamoto and T. Sueyoshi et al., 2002. Diverse roles of the nuclear orphan receptor CAR in regulating hepatic genes in response to phenobarbital. Mol. Pharmacol., 61: 1-6. DOI: 10.1124/mol.61.1.1

Wacher, V.J., C.Y. Wu and L.Z. Benet, 1995. Overlapping substrate specificities and tissue distribution of cytochrome P450 3A and Pglycoprotein: Implications for drug delivery and activity in cancer chemotherapy. Mol. Carcinog., 13: 129-134. PMID: 7619215 
Wojcikowski, J., A. Haduch and W.A. Daniel, 2012. Effect of classic and atypical neuroleptics on cytochrome P450 3A (CYP3A) in rat liver. Pharmacol. Rep., 64: 1411-1418. PMID: 23406751

Xie, W., J.L. Barwick, C.M. Simon, A.M. Pierce, S. Safe and B. Blumberg et al., 2000. Reciprocal activation of xenobiotic response genes by nuclear receptors SXR/PXR and CAR. Genes Dev., 14: 3014-3023. DOI: $10.1101 /$ gad. 846800
Zaher, H., T.J. Yang, H.V. Gelboin, P. FernandezSalguero and F.J. Gonzalez, 1998. Effect of phenobarbital on hepatic CYP1A1 and CYP1A2 in the Ahr-null mouse. Biochem. Pharmacol., 55: 235238. DOI: 10.1016/S0006-2952(97)00476-0

Zanger, U.M., K. Klein and M. Schwab, 2008. In reply. Am. Soc. Clin. Oncol., 26: 4998-4999. DOI: 10.1200/JCO.2008.18.8714 